\title{
MG132 enhances the radiosensitivity of lung cancer cells in vitro and in vivo
}

\author{
WEI ZHU ${ }^{1,2}$, JING LIU $^{1,2}$, JIHUA NIE $^{1-3}$, WENJIONG SHENG ${ }^{1,2}$, HAN CAO $^{1}$, WENHAO SHEN $^{1}$, AIJING DONG $^{1,2}$, \\ JUNDONG ZHOU ${ }^{4}$, YANG JIAO ${ }^{1,2}$, SHUYU ZHANG ${ }^{1,2^{*}}$ and JIANPING CAO $\mathrm{ZH}^{1,2^{*}}$ \\ ${ }^{1}$ School of Radiation Medicine and Protection and Jiangsu Provincial Key Laboratory of Radiation Medicine \\ and Protection, Medical College of Soochow University; ${ }^{2}$ Collaborative Innovation Center of Radiation Medicine \\ of Jiangsu Higher Education Institutions and School for Radiological and Interdisciplinary Sciences (RAD-X), \\ Soochow University; ${ }^{3}$ School of Public Health, Medical College of Soochow University, Suzhou, Jiangsu 215123; \\ ${ }^{4}$ The Core Laboratory of Suzhou Cancer Center and Department of Radiotherapy of Suzhou Municipal Hospital, \\ Suzhou, Jiangsu 215001, P.R. China
}

Received May 6, 2015; Accepted July 3, 2015

DOI: 10.3892/or.2015.4169

\begin{abstract}
Radiotherapy is a common treatment modality for lung cancer, however, radioresistance remains a fundamental barrier to attaining the maximal efficacy. Cancer cells take advantage of the ubiquitin-proteasome system (UPS) for increased proliferation and decreased apoptotic cell death. MG132 (carbobenzoxyl-leucinyl-leucinyl-leucinal-H), a specific and selective reversible inhibitor of the $26 \mathrm{~S}$ proteasome, has shown anticancer effect in multiple types of cancers. Previously, we have reported that MG132 enhances the anti-growth and anti-metastatic effects of irradiation in lung cancer cells. However, whether MG132 can enhance the radiosensitivity in lung cancer cells in vitro and in vivo is still unknown. In this study, we found that MG132 increased apoptosis and dicentric chromosome ratio of A549 and H1299 cells treated by irradiation. Radiation-induced $\mathrm{NF}-\kappa \mathrm{B}$ expression and $\mathrm{I} \kappa \mathrm{B} \alpha$ phosphorylation was attenuated in MG132 plus irradiation-treated cells. The in vivo model of H1299 xenografts of nude mice showed that the tumor size of MG132 plus irradiation treated xenografts was smaller than that of irradiation, MG132 or the control group. Moreover, MG132 plus irradiation group showed significant reduced Ki67 expression. Taken
\end{abstract}

Correspondence to: Professor Shuyu Zhang or Professor Jianping Cao, School of Radiation Medicine and Protection and Jiangsu Provincial Key Laboratory of Radiation Medicine and Protection, Medical College of Soochow University, 199 Ren'ai Road, Suzhou, Jiangsu 215123, P.R. China

E-mail: zhang.shuyu@hotmail.com

E-mail:.jpcao@suda.edu.cn

*Contributed equally

Key words: lung cancer, MG132, radiosensitivity together, these results demonstrate that MG132 enhances the radiosensitivity through multiple mechanisms in vitro and in vivo.

\section{Introduction}

Lung cancer is the leading cause of cancer-related deaths worldwide and radiotherapy has been an important treatment modality for this disease $(1,2)$. However, the prognosis of lung cancer remains unsatisfactory. The emergence of radioresistance remains a fundamental barrier to attaining the maximal efficacy during radiotherapy. Therefore, improving tumor radiosensitivity and reducing radioresistance offers promise for lung cancer therapy $(3,4)$. Studies have showed that combined treatment of irradiation with chloroquine, phenformin significantly increased lung cancer cell radiosensitivity $(5,6)$.

The ubiquitin-proteasome system (UPS) degrades over $85 \%$ of intracellular proteins. Cancer cells take advantage of the UPS for their increased proliferation and decreased apoptotic cell death (7). MG132 (carbobenzoxyl-leucinyl-leucinyl-leucin al-H) is a specific proteasome inhibitor of the $26 \mathrm{~S}$ proteasome. MG132 can induce apoptosis in human esophageal squamous cell carcinoma, leukemia, pancreatic cancer, glioblastoma and hypopharyngeal cancer by inhibiting the nuclear translocation of Akt, NF- $\kappa \mathrm{B}$ and mTOR signaling (7-11). MG132 is also implicated in the radiosensitivity of cancer cells. It was reported that MG132 sensitizes prostate cancer cells to irradiation via $\mathrm{NF}-\kappa \mathrm{B}$ inhibition $(12,13)$. In addition, MG132 can improve the radiotherapeutic effect in NSCLC through the antioxidant mechanism (14). Our previous study further showed that MG132 enhanced the anti-growth and anti-metastatic effects of irradiation in NSCLC cells by modulating expression of cell cycle- and invasion-related genes (15). Although a few studies have shown that MG132 can modulate the radiosensitivity of cancer cells, its underlying mechanisms remain incomplete. In this study, we investigated the MG132 capable of suppressing proliferation and $\mathrm{NF}-\kappa \mathrm{B}$ on radiosensitivity; it may be valuable in the prevention of A549 and H1299 cell growth. 


\section{Materials and methods}

Cell culture and irradiation treatment. Lung cancer cell lines A549 and H1299 were maintained in Dulbecco's modified Eagle's medium (DMEM) containing 10\% fetal bovine serum (FBS) (both from Hyclone, Logan, UT, USA), $100 \mathrm{U} / \mathrm{ml}$ penicillin and $100 \mu \mathrm{g} / \mathrm{ml}$ streptomycin at $37^{\circ} \mathrm{C}$ in a humidified $5 \%$ $\mathrm{CO}_{2}$ incubator. MG132 (Sigma-Aldrich, St. Louis, MO, USA) was dissolved in dimethyl sulfoxide (DMSO) and diluted by DMEM to different concentrations. Cells were divided into 4 groups: control group, MG132-treated group, irradiation alone and MG132 plus irradiation group. Briefly, exponentially growing cells were exposed to different doses of ionizing radiation using X-ray linear accelerator ( $\operatorname{Rad}$ Source, Suwanee, GA, USA) at a fixed dose rate of $1.15 \mathrm{~Gy} / \mathrm{min}$. Control cells were defined as 0 Gy group. Cells were treated with $200 \mu$ M MG132 and irradiated $6 \mathrm{~h}$ later as previously reported (15).

Cell viability assay. Cell viability was determined using the 3-(4,5-dimethylthiazol-2-yl)-2,5-diphenyltetrazolium bromide (MTT) assay. Cells were seeded in 96-well plates at a density of $2.5 \times 10^{3} /$ well 1 day prior to treatment. Then, cells were treated with MG132 or/and irradiation. After treatment, $20 \mu \mathrm{lof} 5 \mathrm{mg} / \mathrm{ml}$ MTT solution was added into each well and incubated for $4 \mathrm{~h}$. After the supernatant was removed, $100 \mu \mathrm{l}$ of DMSO was added, and then placed in a microplate reader to measure OD value. Cell viability rate (VR) was calculated according to the following formula: $\mathrm{VR}=(\mathrm{OD}$ in observed group/OD in 0 Gy group) $x 100 \%$. All assays were repeated 3 times in quintuplicate.

Measurement of apoptosis. Cells were treated with MG132 for $24 \mathrm{~h}$ prior to irradiation. Apoptosis was measured using propidium iodide (PI)/Annexin V double staining (Keygen, Nanjing, China). Apoptotic fractions were measured using flow cytometry (Beckman, USA). The Annexin $\mathrm{V}^{+} / \mathrm{PI}^{-}$cells are early in the apoptotic process, the Annexin $\mathrm{V}^{+} / \mathrm{PI}^{+}$cells indicating late apoptosis. The percentage of both kinds of cells was counted.

Western blot analysis. Cells were harvested at $48 \mathrm{~h}$ after treatment with MG132 or 8 Gy irradiation. Cells were then incubated with ice-cold RIPA buffer $(50 \mathrm{mM}$ Tris, $\mathrm{pH} 7.2$, $150 \mathrm{mM} \mathrm{NaCl}, 1 \% \mathrm{NP}-40,1 \%$ sodium deoxycholate, $0.05 \%$ SDS, and $1 \mathrm{mM}$ PMSF) on ice. The supernatants obtained after centrifugation were quantified with an enhanced BCA protein assay kit (Beyotime, Nantong, China). Proteins were separated by sodium dodecyl sulfate-polyacrylamide gel electrophoresis (SDS-PAGE) through 10\% gel and transferred to polyvinylidene fluoride (PVDF) membrane. Membrane was blocked with 5\% skim milk in PBS containing 0.1\% Tween-20 (PBST) for $1 \mathrm{~h}$ at room temperature. Membrane was probed with antibodies against NF- $\kappa \mathrm{B}, \mathrm{I} \kappa \mathrm{B} \alpha(\mathrm{pS} 36)$ and lamin B1 overnight at $4^{\circ} \mathrm{C}$. Antibodies against NF- $\mathrm{KB}$ and $\mathrm{I} \kappa \mathrm{B} \alpha(\mathrm{pS} 36)$ were obtained from Santa Cruz Biotechnology (Santa Cruz, CA, USA). Membrane was washed 3 times in PBST and incubated with peroxidase-conjugated mouse or rabbit secondary antibody for $2 \mathrm{~h}$ at room temperature. Membrane was washed in PBST, and the detection was done using enhanced chemiluminescence. The analysis of relative protein expression level was performed using Image $\mathbf{J}$ software (National Institute of Health, Bethesda, MD, USA).

Detection of cell dicentric chromosome ratio. After irradiation, cells were treated with $400 \mathrm{ng} / \mathrm{ml}$ colchicines (Sangon, Shanghai, China) and incubated for $8 \mathrm{~h}$ in an incubator. Cells were harvested; $20 \mathrm{~min} 75 \mathrm{mM} \mathrm{KCl}$ low permeability, and fix in methanol and glacial acetic acid (3:1), stained with $10 \%$ Giemsa (pH 7.4). About 600 cells were observed in each group.

Xenograft tumorigenicity assay in nude mice. All animal experiment protocols in this study were carried out in accordance with a protocol approved by the Institutional Ethics Committee. Twenty-four nude mice were obtained from the Laboratory Animal Center of Shanghai (Shanghai, China) and divided into 4 groups: i), control group with mock treatment; ii), radiation group (IR) with 2 Gy/day X-ray irradiation for 5 days; iii), MG132 group; and iv), MG132 plus irradiation group. H1299 cells $\left(1 \times 10^{8}\right)$ were subcutaneously injected into the hind leg near the spine, in nude mice, respectively. The body weight and tumor volume of nude mice were measured at 2 day intervals for 3 weeks. On day 22, the animals were sacrificed and tumors were resected to perform immunohistochemistry (IHC).

Immunohistochemistry. The tissue samples were fixed in $10 \%$ neutral-buffered formalin and embedded in paraffin. Three-micrometer-thick paraffin sections were deparaffinized, dehydrated, and heat-treated with citrate buffer ( $\mathrm{pH}$ 6.0) for $15 \mathrm{~min}$ as an epitope retrieval protocol. The endogenous peroxidase activity was blocked with $3 \%$ hydrogen peroxide for $30 \mathrm{~min}$, and the non-specific binding sites were blocked with $4 \%$ skim milk powder for $30 \mathrm{~min}$. After three washes in phosphate-buffered saline, the sections were incubated with a Ki67 antibody (dilution 1:200; Cell Signaling Technology, Boston, MA, USA) overnight at $4^{\circ} \mathrm{C}$. The sections were mixed with $2 \%$ skim milk powder to reduce non-specific staining, and a biotinylated secondary antibody was added for $30 \mathrm{~min}$. Avidin-biotin-peroxidase complex (Dako LSAB2 system; Dako Co., Carpinteria, CA, USA) was added, and the color was developed using 3-3'-diaminobenzidine. Counterstaining was performed with hematoxylin. All steps were carried out at room temperature. The positive cells were counted by Image J software.

Statistical analysis. Statistical analysis was performed with the use of SAS 8.0 statistical software. Data are presented as means \pm SEM. The Student's t-test was used to measure the difference between the two groups. The differences between more than two groups were tested for significance using one-way analysis of variance. $\mathrm{P}<0.05$ was considered statistically significant.

\section{Results}

MG132 increases the radiosensitivity in lung cancer cells. Previously, we have determined that MG132 at non-toxic dose $(200 \mathrm{nM})$ enhanced the anti-growth and anti-invasion induced by irradiation (15). To assess whether this dose of MG132 modulates the radiosensitivity of A549 and H1299 cells, we 

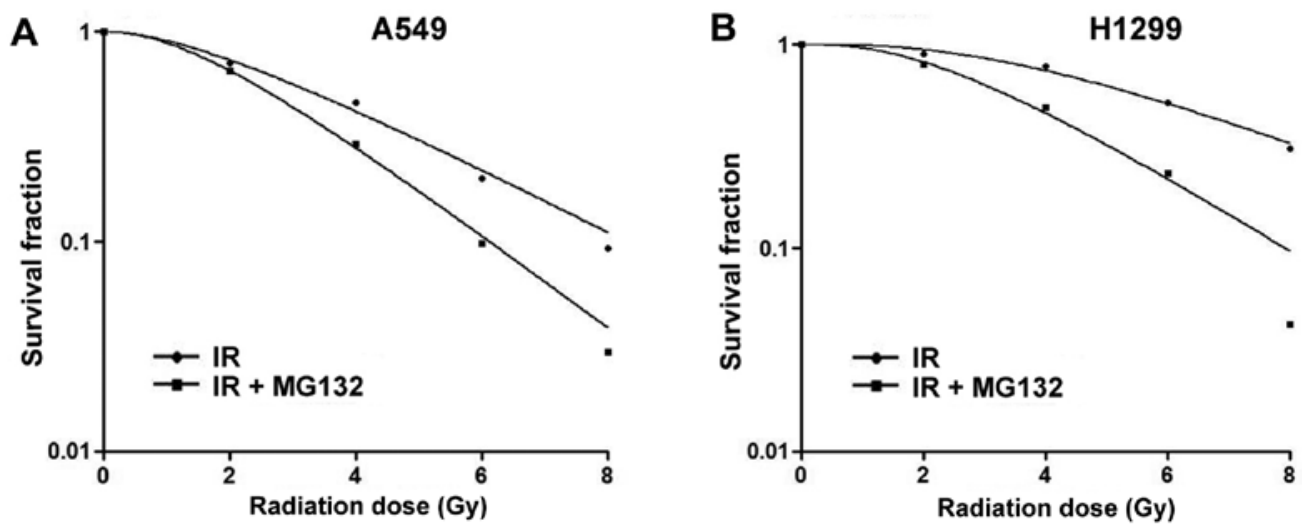

\begin{tabular}{llll}
\hline groups & $D_{0}$ & $D_{q}$ & $\mathrm{~N}$ \\
\hline IR & 2.80 & 1.91 & 3.40 \\
IR+MG132 & 1.95 & 1.70 & 3.16 \\
SER & 1.44 & & \\
\hline
\end{tabular}

\begin{tabular}{llll}
\hline groups & $\mathrm{D}_{0}$ & $\mathrm{D}_{\mathrm{q}}$ & $\mathrm{N}$ \\
\hline IR & 3.63 & 4.44 & 3.40 \\
IR+MG132 & 2.32 & 2.67 & 3.16 \\
SER & 1.56 & & \\
\hline
\end{tabular}

Figure 1. MG132 sensitized A549 and H1299 cells to X-ray irradiation. Clonogenic cell survival curves were generated for (A) A549 and (B) H1299 cells that were treated with MG132 for $6 \mathrm{~h}$ and then exposed to 2, 4, 6 or 8 Gy IR. The survival data were normalized to those of the unirradiated control group. The SER was calculated according to the multi-target single hit model. IR, irradiation; SER, sensitizer enhancement ratio.
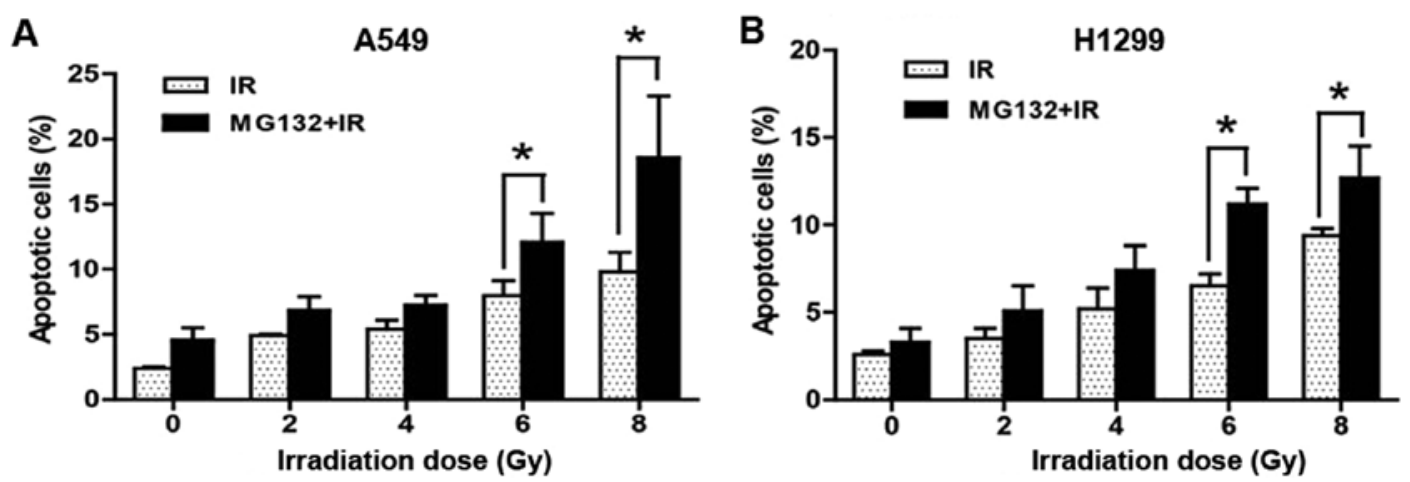

Figure 2. MG132 enhanced apoptosis and dicentric chromosome ratio induced by irradiation in A549 and H1299 cells. Cells were treated with MG132 for $6 \mathrm{~h}$ prior to treatment with IR. Apoptosis and necrosis were measured using PI/Annexin V double staining in (A) A549 and (B) H1299 cells. The data are shown as means \pm SEM for three independent experiments. Statistical analysis between the groups was determined by ANOVA; ${ }^{*} \mathrm{P}<0.05$. IR, irradiation; PI, propidium iodide.

analyzed colony formation after various doses of irradiation. As shown in Fig. 1, the survival fraction was significantly decreased in both cells, especially in MG132 plus irradiation group. The mean lethal dose $\left(\mathrm{D}_{0}\right)$ of the irradiation group and MG132 plus irradiation group in A549 cell line were 2.8 and $1.95 \mathrm{~Gy}$, respectively. The mean lethal dose $\left(\mathrm{D}_{0}\right)$ in H1299 was 3.63 and $2.32 \mathrm{~Gy}$, respectively. Moreover, the quasi-threshold doses $\left(\mathrm{D}_{\mathrm{q}}\right)$ were 1.91 and $1.70 \mathrm{~Gy}$ for A549 cells, and 4.44 and 1.67 Gy for H1299 cells. The sensitizer enhancement ratio (SER) was 1.44 (A549) and 1.56 (H1299) for cells pretreated with MG132, compared to the control cells. Thus, MG132 sensitized A549 and H1299 cells to irradiation.

MG132 enhanced apoptosis induced by irradiation. We next investigated whether reduced clonogenic survival upon combined treatment with MG132 and X-ray irradiation was associated with increased apoptosis. As shown in Fig. 2, 6 or 8 Gy X-ray irradiation obviously induced apoptosis (Annexin $\mathrm{V}^{+} / \mathrm{PI}^{-}$plus Annexin $\mathrm{V}^{+} / \mathrm{PI}^{+}$cells) in both A549 and H1299 cell lines. MG132 treatment further enhanced the apoptotic response of cells to 6 or 8 Gy irradiation. In comparasion, there was no significant difference in apoptotic fraction between irradiation and MG132 plus irradiation at 2 or 4 Gy irradiation. Taken together, these results demonstrate that MG132 augments apoptotic cell death of A549 and H1299 cells in response to irradiation.

MG132 increased the dicentric chromosome ratio treated by irradiation in H1299 cells. Dicentric chromosomes ratio was used to detect chromosome aberration in irradiated cells (16). In this study, dicentric chromosome ratio was determined in H1299 cells after irradiation with or without MG132. As 
A

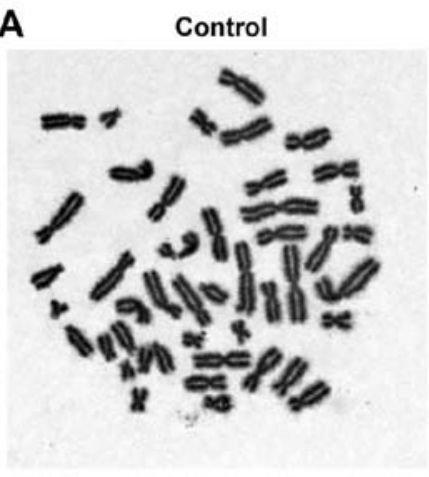

IR

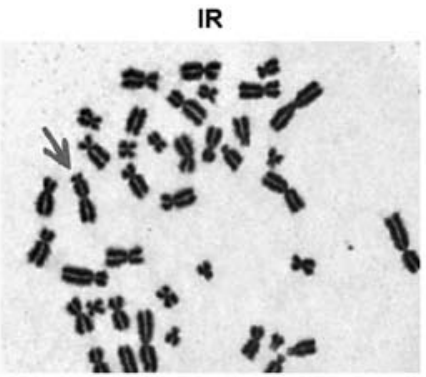

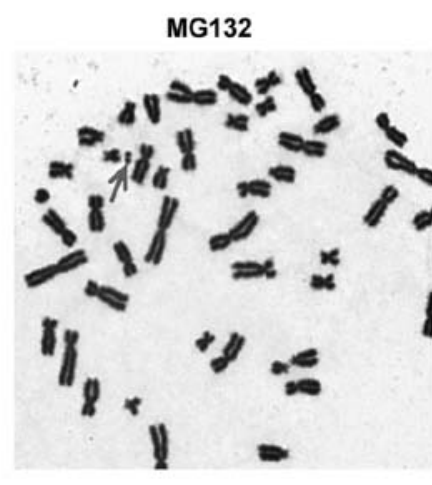

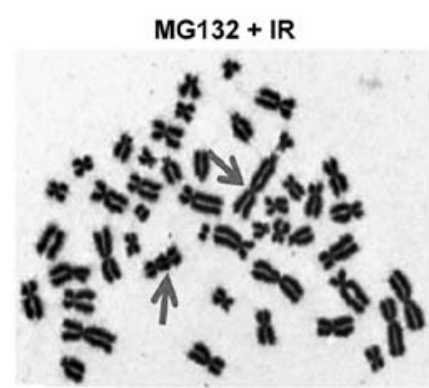

B

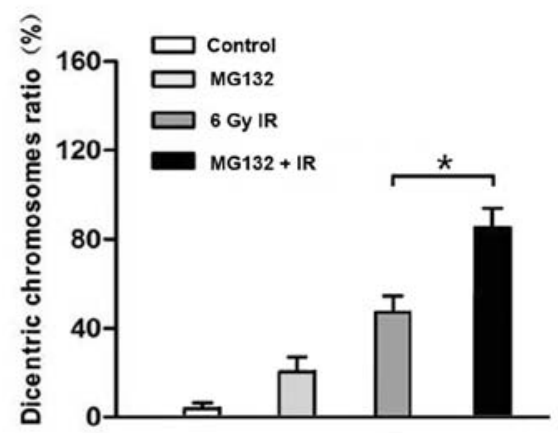

Figure 3. MG132 modulated dicentric chromosome ratio. After indicated doses of irradiation (IR), H1299 cells were treated with colchicines and incubated. Cells were then harvested to observe the changes in the chromosomes. About 600 cells were observed in each group. (A) Representative chromosome image in each group. (B) The calculated dicentric chromosome ratio in each group. The data are shown as mean \pm SEM for three independent experiments. Statistical analysis between the groups was determined by ANOVA; ${ }^{*} \mathrm{P}<0.05$.

A

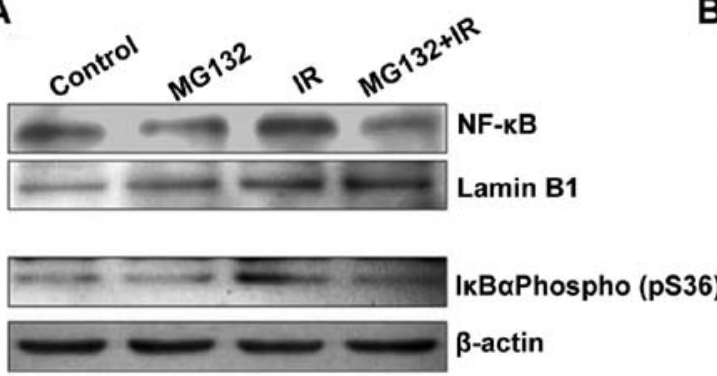

B

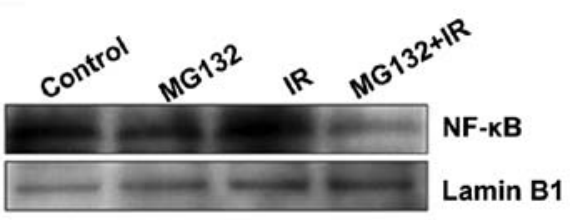

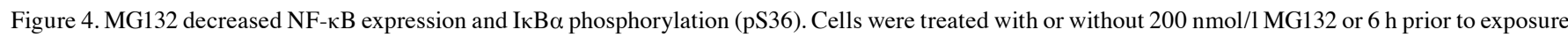

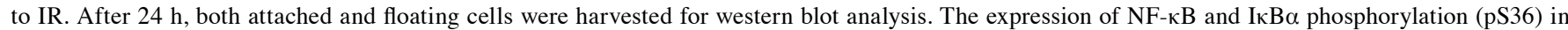
(A) 549 and (B) H1299 cells was detected by western blot analysis. IR, irradiation.

shown in Fig. 3, we found that the dicentric chromosome aberration ratio in MG132 plus irradiation group was higher than of irradiation alone group, suggesting that chromosomes were severely damaged and a positive dose-response relationship exists between dicentric chromosome ratio and the irradiation dose.

MG132 inhibits $N F-\kappa B$ activation by irradiation. $N F-\kappa \mathrm{B}$ is a crucial transcription factor that regulates the expression of genes linked to apoptosis, survival, proliferation, invasion, metastasis and tumor cell transformation $(17,18)$. NF- $\kappa \mathrm{B}$ has been extensively reported to be implicated in cancer cell radiosensitivity due to their role of transcriptional regulation upon radiation exposure. To further confirm the effect of MG132 on $\mathrm{NF}-\kappa \mathrm{B}$ activity induced by irradiation, we analyzed the expression level of NF- $\mathrm{KB}$ (p65 subunit) in A549 and H1299 cells.
As shown in Fig. 4, the expression of NF- $\kappa \mathrm{B}$ in the nuclear extracts of the both cell lines were increased after irradiation, while addition of MG132 decreased radiation-induced NF- $\kappa \mathrm{B}$ (p65) expression in the nucleus. Phosphorylation of $\mathrm{I} \kappa \mathrm{B} \alpha$, which mediates the degradation of $\mathrm{I} \kappa \mathrm{B} \alpha$ and activates $\mathrm{NF}-\kappa \mathrm{B}$, was decreased, suggesting decreased $N F-\kappa B$ expression was attributed to reduced degradation of $\mathrm{I} \kappa \mathrm{B} \alpha$.

Irradiation combined with MG132 inhibits the growth of H1299 xenografts. We next sought to determine the effect of MG132 on H1299 cells by tumor growth in nude mice. Mice were divided into 4 groups: i), control group with mock treatment; ii), radiation group (IR) with 2 Gy/day X-ray irradiation for 5 days; iii), MG132 group; and iv), MG132 plus irradiation group. H1299 cells were subcutaneously innoculated into nude mice. As shown in Fig. 5A, there was no significant differ- 
A

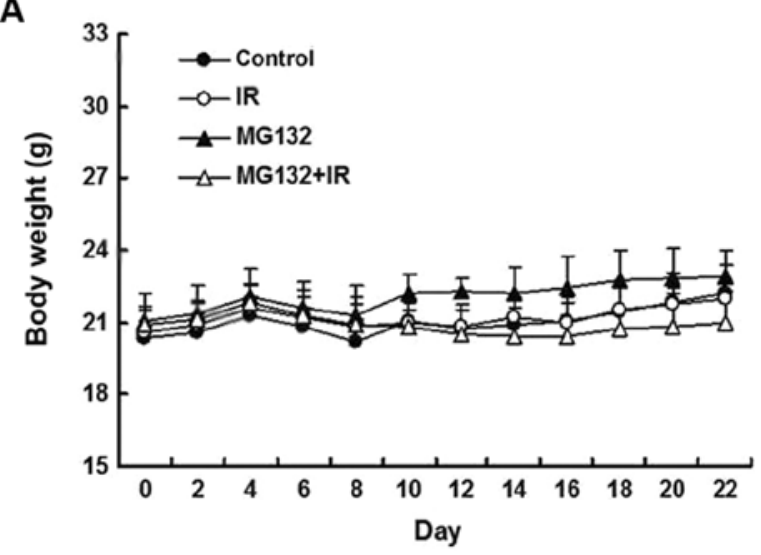

B

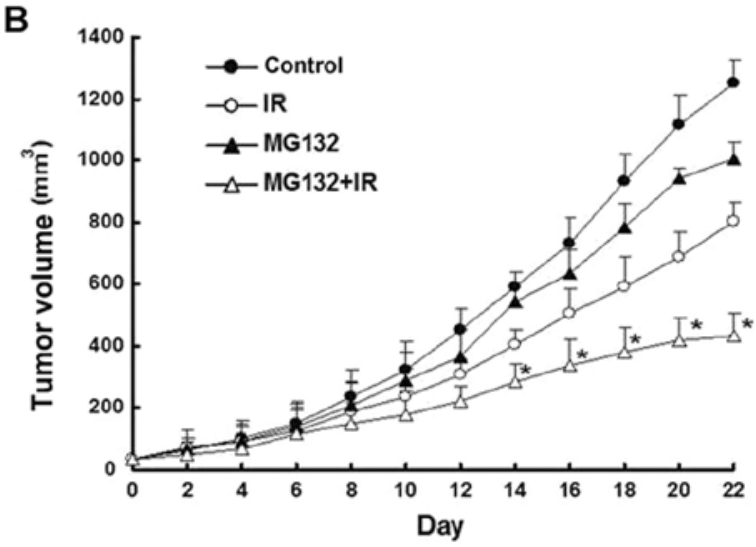

C

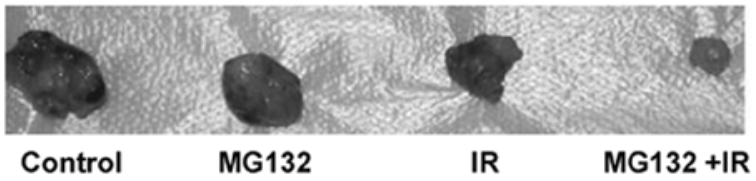

Figure 5. MG132 sensitized H1299 xenografts of nude mice to X-ray irradiation in vivo. Each group of mice was composed of six male nude mice. H1299 cells were inoculated under the skin of nude mice. The body weight and tumor size was measured at 2 day intervals. "P<0.05, compared with IR alone group. (A) The body weight of nude mice in each group. (B) The volume and size of tumors. (C) Representative tumor xenograft of each group. IR, irradiation.

A

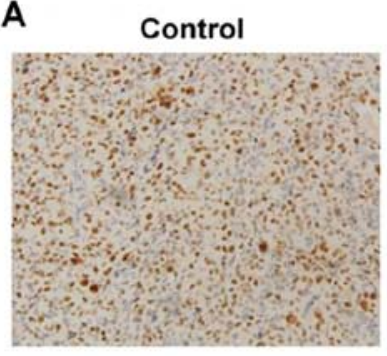

IR

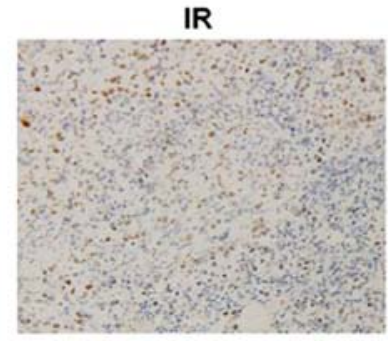

MG132

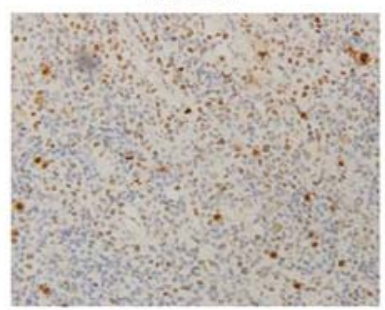

$M G 132+I R$

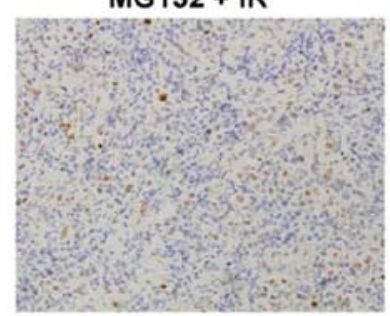

B

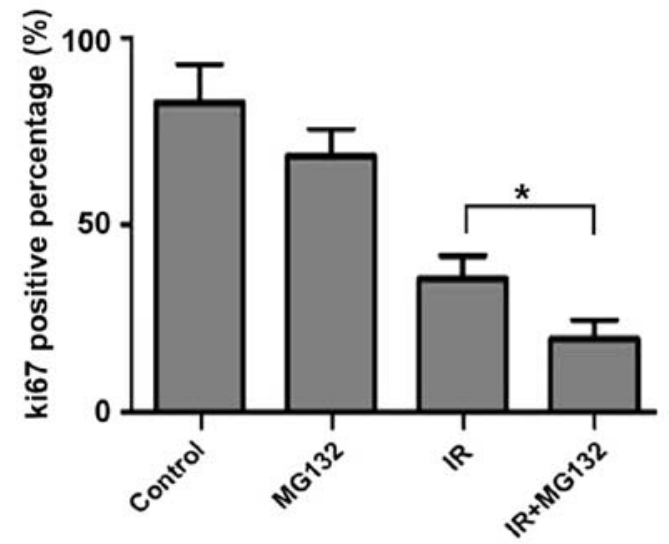

Figure 6. The effect of MG132 on Ki67 expression. (A) Representative IHC showing Ki67 expression in H1299 xenografts (magnification, x400). (B) Percentage of Ki67-positive cells per field are expressed as means \pm SEM. ${ }^{*} \mathrm{P}<0.05$, compared with IR alone group. The Ki67-positive brown cells were calculated by Image J software. IR, irradiation; IHC, immunohistochemistry.

ence in the weight of nude mice between groups. As shown in Fig. 5B, mice treated with MG132 alone yielded $19.58 \%$ inhibition of tumor volume as the control group. Compared with the control group, the tumor volume of mice treated with radiation alone was reduced by $35.70 \%$. Comparatively, H1299 xenografts that received combined treatment of 10 Gy radiation and MG132 exhibited much smaller tumors compared with mice that received radiation alone (volume reduction of $62.75 \%$ in IR + MG132 group). The expression of Ki67 from xenografts was analyzed by IHC. Ki67 expression was observed by a microscope (HE; magnification, x400). As shown in Fig. 6, Ki67-positive cells were significant decreased in MG132 plus irradiation groups compared with control group. Taken together, these results indicate that MG132 can enhance radiosensitivity of $\mathrm{H} 1299$ xenografts.

\section{Discussion}

Radiotherapy has been extensively used to cure various types of cancers, such as lung, breast, oesophageal, prostate and head and neck cancer (19-23), however, the efficacy after radiotherapy cannot be completely satisfactory due to radioresistance. Radiosensitizer in combination with radiotherapy has shown promise to improve the radiotherapy effects. For 
example, cannabinoids can prime glioma cells to respond better to ionizing radiation (24) and AZD3965 with fractionated radiation was used to treat small cell lung cancer (25). In this study, MG132 was used to enhance the radiosensitivity. Survival fraction and apoptosis are used to explain the degree of damage by irradiation. We found the survival fraction of irradiation plus MG132 group was lower than of the MG132 alone group in both A549 and H1299 cells. Apoptotic percentage of cells were higher than irradiation group cells. These results suggested that it is feasibly to improve the radiosensitivity for reducing the survival rate and increasing apoptosis by using drugs.

Dicentric chromosome, as one of chromosome aberrations, is a chromosome containing two functional centromeres and considered to be the most accurate method for biological dosimetry in irradiation $(16,26,27)$. It was reported that dicentric chromosome was frequently observed in cancer cells $(28,29)$ and chromosomal rearrangements can radically alter gene products and their function, driving tumor formation or progression (30). In our study, dicentric chromosome ratio was significantly decreased when treated MG132. This result suggests that MG132 could alleviate the damage on the chromosome.

$\mathrm{NF}-\mathrm{\kappa B}$ was activated by irradiation and plays a key role in radio-adaptive resistance under ionizing radiation in prostate and breast cancer (31-33). However, the activation of NF- $\mathrm{KB}$ could reduce the therapeutic efficacy of radiotherapy in cancer cells (34) and blocking NF- $\mathrm{KB}$ activation increased the apoptosis response $(35,36)$. In this study, activation of NF- $\mathrm{KB}$ was found and the expression of NF- $\mathrm{kB}$ was decreased by using MG132 in A549 and H1299 cell lines. This result suggested that activation of NF- $\mathrm{kB}$ can be inhibited by MG132 treatment with irradiation. Moreover, NF- $\kappa \mathrm{B}$-binding protein I $\kappa \mathrm{B} \alpha$ pS36 was activated by phosphorylation, and the expression of I $\mathrm{KB} \alpha-\mathrm{pS} 36$ has the same trend with NF- $\mathrm{kB}$.

Lung cancer xenograft model of nude mice was used to determine the radiosensitizing effect of MG132 in vivo. Our study showed that the tumor volume in MG132 plus irradiation group was significant smaller than other groups. This result strongly suggests that MG132 combination with radiotherapy could be developed into a useful therapy for lung cancer. Ki67 is recognized as a useful marker for proliferation of tumor cells $(37,38)$, and it is synthesized at the beginning of cell proliferation and expressed in G1, G2 and S phases (39). Ki67 is a well-established prognostic and predictive marker (40). Our study suggested that malignancy of tumor cells were significant inhibited by irradiation combined with MG132.

In conclusion, these findings indicate that proteasome inhibitor MG132 may promote irradiation-induced apoptosis by inhibiting the activation of NF- $\mathrm{KB}$ and the growth of tumor cells. This study provides a novel and promising therapeutic strategy which is likely to benefit the radiotherapy of lung cancer patients.

\section{Acknowledgements}

This study was supported by the National Natural Science Foundation of China (nos. 81472917, 81372433 and 81402626), the Natural Science Fund for Colleges and Universities in Jiangsu Province (12KJB330005) and the Priority Academic
Program Development of Jiangsu Higher Education Institutions (PAPD).

\section{References}

1. Siegel R, Ma J, Zou Z and Jemal A: Cancer statistics, 2014. CA Cancer J Clin 64: 9-29, 2014.

2. Machtay M, Paulus R, Moughan J, Komaki R, Bradley JE, Choy H, Albain K, Movsas B, Sause WT and Curran WJ: Defining local-regional control and its importance in locally advanced non-small cell lung carcinoma. J Thorac Oncol 7: 716-722, 2012.

3. Choi EK, Terai K, Ji IM, Kook YH, Park KH, Oh ET, Griffin RJ, Lim BU,Kim JS,Lee DS, et al: Upregulation of NAD(P)H:quinone oxidoreductase by radiation potentiates the effect of bioreductive beta-lapachone on cancer cells. Neoplasia 9: 634-642, 2007.

4. Jeong SY, Park SJ, Yoon SM, Jung J, Woo HN, Yi SL, Song SY, Park HJ, Kim C, Lee JS, et al: Systemic delivery and preclinical evaluation of $\mathrm{Au}$ nanoparticle containing beta-lapachone for radiosensitization. J Control Release 139: 239-245, 2009.

5. Wang J, Xia S and Zhu Z: Synergistic effect of phenformin in non-small cell lung cancer (NSCLC) ionizing radiation treatment. Cell Biochem Biophys 71: 513-518, 2015.

6. Zou YM, Hu GY, Zhao XQ, Lu T, Zhu F, Yu SY and Xiong H: Hypoxia-induced autophagy contributes to radioresistance via c-Jun-mediated beclin1 expression in lung cancer cells. J Huazhong Univ Sci Technolog Med Sci 34: 761-767, 2014.

7. Dang L, Wen F, Yang Y, Liu D, Wu K, Qi Y, Li X, Zhao J, Zhu D, Zhang C, et al: Proteasome inhibitor MG132 inhibits the proliferation and promotes the cisplatin-induced apoptosis of human esophageal squamous cell carcinoma cells. Int J Mol Med 33: 1083-1088, 2014

8. Ma J, Yu L, Tian J, Mu Y, Lv Z, Zou J, Li J, Wang H and Xu W: MG132 reverse the malignant characteristics of hypopharyngeal cancer. Mol Med Rep 9: 2587-2591, 2014.

9. Ortiz-Lazareno PC, Bravo-Cuellar A, Lerma-Díaz JM, Jave-Suárez LF, Aguilar-Lemarroy A, Domínguez-Rodríguez JR, González-Ramella O, De Célis R, Gómez-Lomelí $\mathrm{P}$ and Hernández-Flores G: Sensitization of U937 leukemia cells to doxorubicin by the MG132 proteasome inhibitor induces an increase in apoptosis by suppressing NF-kappa B and mitochondrial membrane potential loss. Cancer Cell Int 14: 13, 2014.

10. Zeng RX, Zhang YB, Fan Y and Wu GL: p62/SQSTM1 is involved in caspase- 8 associated cell death induced by proteasome inhibitor MG132 in U87MG cells. Cell Biol Int 38: 1221-1226, 2014.

11. Deeb D, Gao X, Liu YB, Pindolia K and Gautam SC: Pristimerin, a quinonemethide triterpenoid, induces apoptosis in pancreatic cancer cells through the inhibition of pro-survival $\mathrm{Akt} / \mathrm{NF}-\kappa \mathrm{B} / \mathrm{mTOR}$ signaling proteins and anti-apoptotic Bcl-2. Int J Oncol 44: 1707-1715, 2014.

12. Pajonk F, van Ophoven A, Weissenberger $\mathrm{C}$ and $\mathrm{McBride} \mathrm{WH}$ : The proteasome inhibitor MG-132 sensitizes PC-3 prostate cancer cells to ionizing radiation by a DNA-PK-independent mechanism. BMC Cancer 5: 76, 2005.

13. Warren G, Grimes K, Xu Y, Kudrimoti M and St Clair W: Selectively enhanced radiation sensitivity in prostate cancer cells associated with proteasome inhibition. Oncol Rep 15: 1287-1291, 2006.

14. Grimes KR, Daosukho C, Zhao Y, Meigooni A and St Clair W: Proteasome inhibition improves fractionated radiation treatment against non-small cell lung cancer: An antioxidant connection. Int J Oncol 27: 1047-1052, 2005.

15. Liu J, Shen W, Tang Y, Zhou J, Li M, Zhu W, Yang H, Wu J, Zhang S and Cao J: Proteasome inhibitor MG132 enhances the antigrowth and antimetastasis effects of radiation in human nonsmall cell lung cancer cells. Tumour Biol 35: 7531-7539, 2014.

16. Letouzey M, Penther D, Roche-Lestienne C, Nelken B, Devoldère C, Vannier JP and Schneider P: Detection of dicentric chromosome $(9 ; 20)$ in paediatric B-cell acute lymphoblastic leukaemia: Prognostic significance. Ann Hematol 34: 187-193 2015.

17. Ahn KS and Aggarwal BB: Transcription factor NF-kappaB: A sensor for smoke and stress signals. Ann NY Acad Sci 1056: 218-233, 2005.

18. Xue J, Dong JH, Huang GD, Qu XF, Wu G and Dong XR: NF-кB signaling modulates radiation induced microglial activation. Oncol Rep 31: 2555-2560, 2014. 
19. Faria SL: Role of radiotherapy in metastatic non-small cell lung cancer. Front Oncol 4: 229, 2014.

20. Okawara G, Mackay JA, Evans WK and Ung YC; Lung Cancer Disease Site Group of Cancer Care Ontario's Program in Evidence-based Care: Management of unresected stage III non-small cell lung cancer: A systematic review. J Thorac Oncol 1: 377-393, 2006.

21. Cao KI, Lebas N, Gerber S, Levy C, Le Scodan R, Bourgier C, Pierga JY, Gobillion A, Savignoni A and Kirova YM: Phase II randomized study of whole-brain radiation therapy with or without concurrent temozolomide for brain metastases from breast cancer. Ann Oncol 26: 89-94, 2015.

22. Dai Y, Li C, Xie Y, Liu X, Zhang J, Zhou J, Pan X and Yang S: Interventions for dysphagia in oesophageal cancer. Cochrane Database Syst Rev 10: CD005048, 2014.

23. Paliwal R, Kumar-Patidar A, Walke R, Hirapara P, Jain S and Raj-Bardia M: Palliative hypo-fractionated radiotherapy in locally advanced head and neck cancer with fixed neck nodes. Iran J Cancer Prev 5: 178-182, 2012.

24. Scott KA, Dalgleish AG and Liu WM: The combination of cannabidiol and $\Delta 9$-tetrahydrocannabinol enhances the anticancer effects of radiation in an orthotopic murine glioma model. Mol Cancer Ther 13: 2955-2967, 2014.

25. Bola BM, Chadwick AL, Michopoulos F, Blount KG, Telfer BA, Williams KJ, Smith PD, Critchlow SE and Stratford IJ: Inhibition of monocarboxylate transporter-1 (MCT1) by AZD3965 enhances radiosensitivity by reducing lactate transport. Mol Cancer Ther 13: 2805-2816, 2014.

26. Pujol M, Barquinero JF, Puig P, Puig R, Caballín MR and Barrios L: A new model of biodosimetry to integrate low and high doses. PLoS One 9: e114137, 2014.

27. Bender MA, Awa AA, Brooks AL, Evans HJ, Groer PG, Littlefield LG, Pereira C, Preston RJ and Wachholz BW: Current status of cytogenetic procedures to detect and quantify previous exposures to radiation. Mutat Res 196: 103-159, 1988.

28. Mackinnon RN and Campbell LJ: The role of dicentric chromosome formation and secondary centromere deletion in the evolution of myeloid malignancy. Genet Res Int 2011: 643628, 2011.

29. Yamamoto K, Matsuoka H, Funakoshi Y, Yakushijin K, Okamura A, Itoh $\mathrm{T}$ and Minami $\mathrm{H}$ : A novel dicentric chromosome, dic $(9 ; 9)(\mathrm{p} 12 ; \mathrm{q} 34)$, leading to trisomy 9 in follicular lymphoma without $\mathrm{t}(14 ; 18)$. Leuk Res 35: e100-e103, 2011.

30. Gascoigne KE and Cheeseman IM: Induced dicentric chromosome formation promotes genomic rearrangements and tumorigenesis. Chromosome Res 21: 407-418, 2013.
31. Sun Y, St Clair DK, Fang F, Warren GW, Rangnekar VM, Crooks PA and St Clair WH: The radiosensitization effect of parthenolide in prostate cancer cells is mediated by nuclear factor-kappaB inhibition and enhanced by the presence of PTEN. Mol Cancer Ther 6: 2477-2486, 2007.

32. Aravindan S, Natarajan M, Herman TS, Awasthi V and Aravindan N: Molecular basis of 'hypoxic' breast cancer cell radio-sensitization: Phytochemicals converge on radiation induced Rel signaling. Radiat Oncol 8: 46, 2013.

33. Kozakai N, Kikuchi E, Hasegawa M, Suzuki E, Ide H, Miyajima A, Horiguchi Y, Nakashima J, Umezawa K, Shigematsu N, et al: Enhancement of radiosensitivity by a unique novel NF- $\mathrm{B}$ inhibitor, DHMEQ, in prostate cancer. Br J Cancer 107: 652-657, 2012.

34. Starenki DV, Namba H, Saenko VA, Ohtsuru A, Maeda S, Umezawa $\mathrm{K}$ and Yamashita S: Induction of thyroid cancer cell apoptosis by a novel nuclear factor kappaB inhibitor, dehydroxymethyl epoxyquinomicin. Clin Cancer Res 10: 6821-6829, 2004.

35. Tang G, Minemoto Y, Dibling B, Purcell NH, Li Z, Karin M and Lin A: Inhibition of JNK activation through NF-kappaB target genes. Nature 414: 313-317, 2001.

36. Chen X, Shen B, Xia L, Khaletzkiy A, Chu D, Wong JY and Li JJ: Activation of nuclear factor kappaB in radioresistance of TP53-inactive human keratinocytes. Cancer Res 62: 1213-1221, 2002.

37. Ji Y, Zheng M, Ye S, Chen J and Chen Y: PTEN and Ki67 expression is associated with clinicopathologic features of non-small cell lung cancer. J Biomed Res 28: 462-467, 2014.

38. Antonarakis ES, Keizman D, Zhang Z, Gurel B, Lotan TL, Hicks JL, Fedor HL, Carducci MA, De Marzo AM and Eisenberger MA: An immunohistochemical signature comprising PTEN, MYC, and Ki67 predicts progression in prostate cancer patients receiving adjuvant docetaxel after prostatectomy. Cancer 118: 6063-6071, 2012.

39. He X, Chen Z, Fu T, Jin X, Yu T, Liang Y, Zhao X and Huang L: $\mathrm{Ki}-67$ is a valuable prognostic predictor of lymphoma but its utility varies in lymphoma subtypes: Evidence from a systematic meta-analysis. BMC Cancer 14: 153, 2014.

40. Yerushalmi R, Woods R, Ravdin PM, Hayes MM and Gelmon KA: Ki67 in breast cancer: Prognostic and predictive potential. Lancet Oncol 11: 174-183, 2010. 